\title{
Synthesis and Activity of Novel Indole Linked Triazole Derivatives as Antifungal Agents
}

\author{
Young Min Na \\ HanWha Pharma Co. Ltd., Yangji R\&D center, $14 F$ Gyunggi Biocenter, Iui Dong, Yeongtong-gu, Suwon, \\ kyunggi-do, Korea.E-mail: youngminna@hotmail.com \\ Received August 2, 2010, Accepted September 15, 2010
}

Key Words: Indole, Triazole, Antifungal, Candida albicans, Aspergillus fumigatus

Systemic fungal diseases continue to be a significant problem in health care today. These infections are often induced by opportunistic causative fungi that are not normally pathogenic and commonly live in the patient's body or are commonly found in the environment. The key opportunistic fungal pathogens were Candida albicans, Aspergillus fumigatus and Cryptococcus spp., which cause mucormycosis, a rapidly fatal infection especially in immunocompromised patients.

The azole antifungals are currently the most widely used and studied class of antifungal agents. Azole compounds prevent the synthesis of ergosterol, a major component of fungal plasma membranes, by inhibiting the cytochrome P-450 dependent enzyme lanosterol demethylase. Their antifungal efficacy is attributed to their greater affinity for fungal P-450 $\mathrm{DM}$ than for the mammalian enzyme. The azole antifungals are classified as imidazoles or triazoles. Generally, use of imidazoles is limited to the treatment of superficial mycoses, whereas the triazoles have a broad range of applications in the treatment of both superficial and systemic infections because of their good affinity for fungal (rather than mammalian cytochrome P-450 enzymes). ${ }^{2}$

Hence, novel triazole compounds are prepared with different substituents on 2-(2,4-difluorophenyl)-2-hydroxy-1-methyl3-(1H-1,2,4-triazol-1-yl)propyl moiety. ${ }^{3}$ The present study on the synthesis and antifungal activity of new voriconazole analogues are incorporated indole derivatives. A variety of indole derivatives with different substituents could exhibit the biological activities through different action and sometimes improve upon the activities. The presence of amino, cyano, halo and alkyl substituents of indoles was considerably important factor to affect their antifungal activity. Based on this speculation, indole-linked triazole derivatives were synthesized and were evaluated for their antifungal activity.

The synthesis of the key intermediate 1, as seen in Scheme 1, may be preceded by well optimized method. ${ }^{4}$ This compound has a chiral center, and the final compounds could be controlled according to the configuration of oxirane. Thus, $(2 R, 3 R)-2-(2,4-$ difluorophenyl)-3-(piperazin-1-yl)-1-(1H-1,2,4-triazol-1-yl) butan-2-ol (2) was prepared using $R$-lactate as a starting material. $R$-lactate was treated firstly with morpholine and then hydroxy group was protected with tetrahydropyrane. The protected compound was reacted with phenylmagnesium bromide, followed by epoxydation (Corey's reagents) to affored the oxirane as a $(2 R, 3 R)$ and $(2 R, 3 S) 4: 1$ diastereomeric mixture. The desired $(2 R, 3 R)$-isomer was isolated by crystallization. The 1,2,4-triazole group was introduced with opening the epoxy ring. The triazole compound was deprotected with $\mathrm{TsOH}$ in $\mathrm{MeOH}$, and then diols compound was mesylated with $\mathrm{MsCl}$ in pyridine. Nucleophilic substitution of mesylated group by means of $\mathrm{NaOMe}$ in $\mathrm{MeOH}$ with concomitant epoxide formation affords the desired intermediate $\mathbf{1}$. Finally piperazine compound 2 was prepared by reacting an oxirane compound with a piperazine in the presence of $\mathrm{LiClO}_{4}$.

The synthesis and functionalization of indoles was performed by well established classical methods. ${ }^{5}$ There are many approaches to the synthesis of indole derivatives which have been categorized into two main types, corresponding to two main sections: the de novo indole system construction from bezenoid precursors through cyclization reactions and the functionalization of performed indole rings as described in Scheme 2.

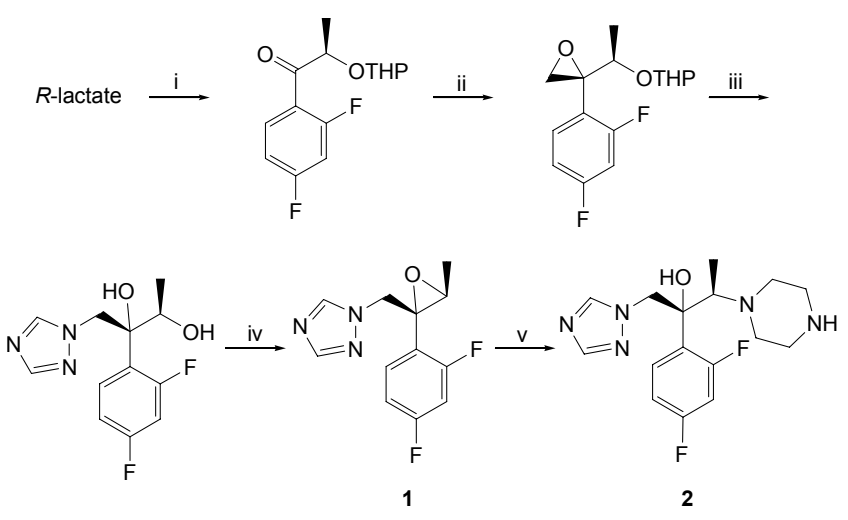

Scheme 1. Synthesis of $(2 R, 3 R)$-2-(2,4-difluorophenyl)-3-(piperazin1-yl)-1-(1H-1,2,4-triazol-1-yl)butan-2-ol (2). Reagents and conditions: (i) morpholine, reflux; 3,4-dihydro-2-pyran, pyridium- $p$-toluenesulfate, $\mathrm{CH}_{2} \mathrm{Cl}_{2}$, rt, $5 \mathrm{~h}, 50 \%$; 1,3-difluorophenylmagnesium bromide, $20{ }^{\circ} \mathrm{C} \rightarrow \mathrm{rt}$, overnight, $95 \%$; (ii) TMSOI, $\mathrm{CH}_{2} \mathrm{Cl}_{2}, 70{ }^{\circ} \mathrm{C}$, overnight, $75 \%$; (iii) 1,2,4-triazole, $\mathrm{K}_{2} \mathrm{CO}_{3}, 100{ }^{\circ} \mathrm{C}, 6 \mathrm{~h}, 96 \%$; (iv) toluenesulfonic acid monohydrate, $\mathrm{MeOH}, \mathrm{rt}, 1 \mathrm{~h}, 61 \%$; $\mathrm{MsCl}$, Pyridine, rt, 6 h, 99\%; $\mathrm{NaOMe}, \mathrm{MeOH}, 0{ }^{\circ} \mathrm{C}, 30 \mathrm{~min}, 81 \%$; (v) piperazine, $\mathrm{LiClO}_{4}, \mathrm{CH}_{3} \mathrm{CN}$, reflux, $50 \%$

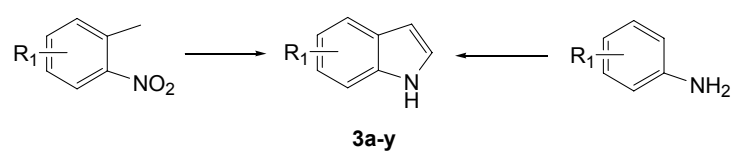

Scheme 2. Synthesis of indole derivatives 
Table 1. in vitro antifungal activity of indole-conazole compounds 4a-y

\begin{tabular}{|c|c|c|c|c|c|c|c|c|}
\hline \multirow[b]{3}{*}{4} & \multirow[b]{3}{*}{$\mathrm{R}_{1}$} & \multicolumn{7}{|c|}{$\mathrm{MIC}_{80}(\mu \mathrm{mol} / \mathrm{mL})^{a}$} \\
\hline & & \multicolumn{4}{|c|}{ C. albicans } & \multirow{2}{*}{$\begin{array}{c}\text { C. krusei } \\
\text { ATCC } 6258\end{array}$} & \multirow{2}{*}{$\begin{array}{l}\text { C. neoformans } \\
\text { ATCC } 36556\end{array}$} & \multirow{2}{*}{$\begin{array}{l}\text { A. fumigatus } \\
\text { ATCC } 16424\end{array}$} \\
\hline & & ATCC 64548 & ATCC 36082 & ATCC MYA-1003 & ATCC 90028 & & & \\
\hline $\mathbf{a}$ & $\mathrm{H}$ & 1.07 & 1.07 & 274 & 0.54 & 34.3 & $>274$ & 137 \\
\hline b & $4-\mathrm{F}$ & 0.52 & 0.52 & 132 & 0.52 & 33.04 & $>529$ & 132 \\
\hline c & 4-Cl & 0.50 & 0.50 & 63.88 & 0.50 & 31.94 & $>511$ & 63.88 \\
\hline d & 4-tetrazole & 59.86 & 59.86 & 239 & 59.86 & $>239$ & $>239$ & $>239$ \\
\hline $\mathbf{e}$ & $5-\mathrm{F}$ & 0.52 & 0.52 & 66.04 & 0.26 & 16.51 & $>264$ & 33.02 \\
\hline f & $5-\mathrm{Cl}$ & 0.25 & 0.25 & 63.88 & 0.25 & 7.98 & $>256$ & 31.94 \\
\hline $\mathbf{g}$ & $5-\mathrm{Br}$ & 0.23 & 0.23 & 29.34 & 0.23 & 1.83 & $>235$ & 7.33 \\
\hline h & $5-\mathrm{Me}$ & 0.52 & 0.26 & 66.59 & 0.26 & 4.16 & $>266$ & 66.59 \\
\hline $\mathbf{i}$ & $5-\mathrm{NO}_{2}$ & 0.24 & 0.24 & 62.56 & 0.24 & 3.91 & $>250$ & 7.82 \\
\hline $\mathbf{j}$ & $5-\mathrm{MeO}$ & 0.5 & 0.5 & 129 & 0.5 & 8.06 & $>258$ & 32.22 \\
\hline $\mathbf{k}$ & $5-\mathrm{N}_{3}$ & 0.25 & 0.25 & 126 & 0.25 & 3.94 & $>252$ & 63.05 \\
\hline 1 & 5-CN & 4.07 & 2.03 & 260 & 2.03 & 65.10 & $>260$ & 65.10 \\
\hline m & 5-CNOH & 31.40 & 31.40 & $>251$ & 31.40 & $>251$ & $>251$ & $>251$ \\
\hline $\mathbf{n}$ & 5-acrylic acid & 119 & 119 & $>239$ & 119 & $>239$ & $>239$ & $>239$ \\
\hline $\mathbf{o}$ & $6-\mathrm{F}$ & 0.52 & 0.26 & 264 & 0.52 & 16.51 & $>264$ & 33.02 \\
\hline $\mathbf{p}$ & $6-\mathrm{Cl}$ & 0.25 & 0.25 & 31.94 & 0.25 & 1.2 & $>256$ & 1.2 \\
\hline$q$ & $6-\mathrm{N} 3$ & 0.25 & 0.25 & 63.05 & 0.25 & 1.97 & $>252$ & 7.88 \\
\hline $\mathbf{r}$ & 6-Me & 0.26 & 0.26 & 66.59 & 0.26 & 4.16 & $>266$ & 16.65 \\
\hline $\mathbf{s}$ & $6-\mathrm{CN}$ & 0.51 & 0.51 & $>260$ & 0.51 & 8.14 & $>260$ & 4.07 \\
\hline $\mathrm{t}$ & $5,6-\mathrm{Cl}$ & 0.23 & 0.23 & 14.94 & 0.23 & 1.87 & $>239$ & 3.74 \\
\hline $\mathbf{u}$ & $7-F$ & 0.52 & 0.26 & 132 & 0.26 & 16.51 & $>264$ & 33.02 \\
\hline $\mathbf{v}$ & $7-\mathrm{Cl}$ & 0.50 & 0.50 & 63.88 & 0.50 & 63.88 & $>511$ & 399 \\
\hline $\mathbf{w}$ & 7-Me & 0.26 & 0.26 & 66.59 & 0.26 & 4.16 & $>266$ & 16.65 \\
\hline $\mathbf{x}$ & 7-CN & 0.25 & 0.25 & 65.10 & 0.25 & 4.07 & $>260$ & 2.03 \\
\hline \multirow[t]{4}{*}{$\mathbf{y}$} & $4,5,6,7-\mathrm{F}$ & 0.23 & 0.23 & 29.27 & 0.23 & 1.86 & $>238$ & 7.43 \\
\hline & Amphotericine B & 0.54 & 0.54 & 0.54 & 0.54 & 1.08 & $>69.26$ & 2.16 \\
\hline & Fluconazole & 0.82 & 0.82 & $>418$ & 0.41 & 104 & $>418$ & $418-836$ \\
\hline & Itraconazole & 0.18 & 0.18 & $>181$ & 0.18 & 0.18 & $>363$ & 0.18 \\
\hline
\end{tabular}

${ }^{a}$ Values are means of three experiments.

Indoles 3a-y were on reaction with formaldehyde in the presence of $\mathrm{AcOH}$ in ethanol at $0{ }^{\circ} \mathrm{C}$ furnished $(2 R, 3 R)-2-(2,4-$ difluorophenyl)-3-[4-(indol-3-ylmethyl) piperazin-1-yl)-1-(1H1,2,4-triazol-1-yl)butan-2-ol 4a-y.

All the newly synthesized compounds $\mathbf{4 a - y}$ was assayed for their antifungal activity against $C$. albicans, $C$. neoformans, $A$. fumigatus and $C$. krusei strains and their $\mathrm{MIC}_{80} \mathrm{~s}$ are summarized in Table 1. The growth inhibition test for drug evaluation against $C$. albicans, $C$. neoformans, $A$. fumigatus and $C$. krusei was carried out by the method based on the National Committee for Clinical Laboratory Standards M27-A and M38-A. Amphotericin $\mathrm{B}$, fluconazole and itraconazole were used as positive controls. 6

The $\mathrm{MIC}_{80}$ values indicate that nearly all the indole derivatives showed excellent antifungal activities against the five yeast Candida species including C. albicans and C. krusei. Noticeably, more than half of 25 compounds showed higher activity aginst $C$. albicans than the tested two conventional drugs such as amphotericin B and fluconazole. These result suggested that introduction of an indole moiety to the triazole pharmacophore strongly enhanced the antifungal activity of these analogs against Candida species. However, C. neoformans was found to be much less sensitive to these indole derivatives.
Compared to their strong activities against yeast species, the $\mathrm{MIC}_{80}$ values indicate that the activities of these indole derivatives against mold fungi are much lower. Only two compounds $(\mathbf{4 p}, \mathbf{4 x})$ showed comparable activities against $A$. fumigatus $\left(\mathrm{MIC}_{80}=1.2\right.$ and $2.16 \mu \mathrm{mol} / \mathrm{mL}$, respectively). The incompetent activity of these indole derivatives against $A$. fumigatus was not a surprise because it has been known that this mold species possesses an intrinsic mechanism resistant to triazole antifungals. $^{7}$

Pharmacomodulation aimed at evaluating the influence of (i) the nature and position of halogen group(s) fixed at the in-

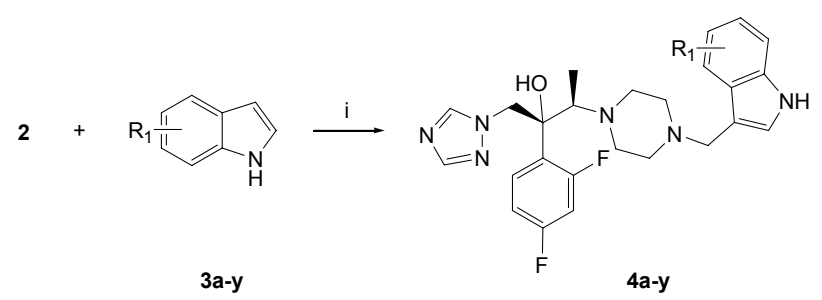

Scheme 3. Synthesis of indole-conazole compounds. Reagents and conditions: i) $\mathrm{HCHO}, \mathrm{AcOH}$, ethanol, $0{ }^{\circ} \mathrm{C} \rightarrow 30-40{ }^{\circ} \mathrm{C}, 12 \mathrm{~h}, 60$ $82 \%$ 
dole ring and (ii) a diverse group(s) at $\mathrm{C} 5$ of indole.

SAR resulting from introducing of an halogen group $\left(\mathrm{R}_{1}\right)$ were explored in the subseries of 4-, 5-, 6- and 7-position on the indole ring. Replacing hydrogen by halogen exerted a favorable effect. 4- $\mathrm{Cl}(\mathbf{4 c}), 5-\mathrm{Cl}(\mathbf{4 f}), 6-\mathrm{Cl}(4 \mathbf{p})$ and 7- $\mathrm{Cl}(\mathbf{4 v})$ were 4-fold as active as $\mathbf{4 a}$ and the substituted indole derivatives $\mathbf{4 b} \mathbf{b}-\mathbf{y}$ were generally more potent than unsubstituted indole compound 4a. Interestingly, the most potent antifungal activity against C. albicans is obtained with halogenated indole derivatives and the antifungal activity against $A$. fumigatus and C. krusei were prominent. In contrast, these indole compounds did not show significant antifungal activity against $C$. neoformans as positive control exhibited poor activities.

Of the 11 halogenated indole derivatives, multi-halogenated compounds (4t, 4y) $\left(\mathrm{MIC}_{80}=0.23-29.27 \mu \mathrm{mol} / \mathrm{mL}\right.$ against $C$. albicans, 1.87 and $1.86 \mu \mathrm{mol} / \mathrm{mL}$ against $C$. krusei, 3.74 and $7.43 \mu \mathrm{mol} / \mathrm{mL}$ against $A$. fumigates, respectively) are effective against both Candida and mold species. Their broad antifungal spectra are comparable to that of amphotericin B, fluconazole and itraconazole. This result suggests that higher lipophilicity given by the halogens group may contribute to the antifungal activity against yeast fungi.

The halogen-moieties of substituents $\left(\mathrm{R}_{1}: \mathrm{F}, \mathrm{Cl}, \mathrm{Br}\right)$ on the 5-position of the indole ring appear to contribute partially to antifungal potency. However, replacing the halogen groups with a heteroatom on the 5-position of indole ring resulted in poor activities. These results indicated that bulky substituents deteriorated the antifungal activity of these triazole analogs against yeast fungi.

The cyano group at the 5, 6, 7-position of the indole ring also appear to contribute to antifungal activity. Especially, the promising results were obtained with compounds $4 \mathbf{s}, \mathbf{4 x}(\mathrm{MIC}=$ $0.25-0.51 \mu \mathrm{mol} / \mathrm{mL}$ against $C$. albicans and $2.03-4.07 \mu \mathrm{mol} /$ $\mathrm{mL}$ against $A$. fumigatus) which have cyano group at the 6- and 7-position of the indole ring.

These data demonstrate that the position and the presence of halogen/cyano group on the indole ring increase the in vitro activity against fungi by comparison with other substituents.

In conclusion, a novel class of antifungal agents was synthesized by a short synthetic sequence and in good to excellent yields. Some of the indole derivatives exhibited good antifungal activity aginst $C$. albicans and two of the compounds (4t, $4 \mathbf{y})$ exhibited excellent anti-Candida activity. Analysis of the activity of this series of compounds against fungi shows a high selectivity of action against $C$. albicans. These compounds seem to be selective of the cytochrome P450-dependent $14 \alpha$-lanosterol demethylase (P-450 DM) of C. albicans. These observations will be very useful in designing newer molecules in the pursuit of more effective antifungal agents.

\section{Experimental Section}

All melting points were measured with Büchi melting point B-545 and are uncorrected. ${ }^{1} \mathrm{H}$ NMR spectra were recorded on a Bruker AC-250 instrument $\left(250 \mathrm{MHz}\right.$ ) using DMSO- $d_{6}$ or $\mathrm{CDCl}_{3}$ with TMS. $R$-Lactate and other reagents were purchased from Aldrich Chemical Co.

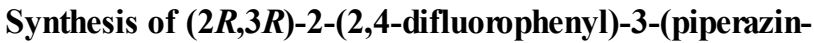

1-yl)-1-(1H-1,2,4-triazol-1-yl)butan-2-ol (2). A mixture of $(2 R, 3 S)-2-(2,4$ difluorophenyl)-3-methyl-2-(1H-1,2,4-triazol1-yl)methyloxirane (1) $(2.0 \mathrm{~g}, 8.0 \mathrm{mmol})$, piperazine $(686 \mathrm{mg}$, $20 \mathrm{mmol})$ and lithium perchlorate $(508 \mathrm{mg}, 12 \mathrm{mmol})$ in acetonitrile $(30 \mathrm{~mL})$ was heated under reflux for $48 \mathrm{~h}$. The solvent was removed under reduced pressure, the residue was treated with crushed ice and extracted with ethyl acetate $(3 \times 30 \mathrm{~mL})$. The combined organic extract was washed with water, brine, dried $\left(\mathrm{Na}_{2} \mathrm{SO}_{4}\right)$ and concentrated to give the desired compound (2) as thick viscous gum (3.0 g, 78\%). ${ }^{1} \mathrm{H}$ NMR $\left(\mathrm{CDCl}_{3}\right) \delta 0.97$ (d, $\left.3 \mathrm{H}, \mathrm{CH}_{3}\right), 2.32-2.42\left(\mathrm{~m}, 2 \mathrm{H}, \mathrm{CH}_{2}\right), 2.66-2.90(\mathrm{~m}, 8 \mathrm{H}, 3 \mathrm{x}$ $\left.\mathrm{CH}_{2}, \mathrm{CH}, \mathrm{OH}\right), 4.36\left(\mathrm{~d}, J=14.0 \mathrm{~Hz}, 1 \mathrm{H}, \mathrm{CH}_{2}\right), 4.57(\mathrm{~d}, J=14.0$ $\mathrm{Hz}, 1 \mathrm{H}, \mathrm{CH}_{2}$ ), 6.68-6.83 (m, 2H, Ar-H), 7.42-7.55 (m, 1H, Ar-H), 7.78 (s, 1H), 8.0 (s, 1H); FAB-MS m/z 337.3 (Calcd. for $\left.\mathrm{C}_{16} \mathrm{H}_{21} \mathrm{~F}_{2} \mathrm{~N}_{5} \mathrm{O}: 337.38\right)$.

Synthesis of (2R,3R)-2-(2,4-difluorophenyl)-3-[4-(5-fluoro$1 H$-indol-3-ylmethyl)-piperazin-1-yl]-1-(1 H-1,2,4-triazol-1yl)butan-2-ol (4e). To a mixed solution of formaldehyde (144 $\mu \mathrm{L})$ and acetic acid $(214 \mu \mathrm{L})$ in ethanol was added $(2 R, 3 R)-2-$ (2,4-Difluorophenyl)-3-(piperazin-1-yl)-1-(1H-1,2,4-triazol1-yl)butan-2-ol (2) $(624 \mathrm{mg})$ at $0{ }^{\circ} \mathrm{C}$. The mixture was stirred for 1 hour, then 5-fluoroindole $(250 \mathrm{mg}$ ) was added. The resulting mixture was stirred for $12 \mathrm{~h}$ at $30-40{ }^{\circ} \mathrm{C}$, and worked up (AcOEt; potassium hydroxide solution, brine). The residue was purified by chromatography on silica gel (dichloromethane : ethanol $=1: 1, \mathrm{v} / \mathrm{v})$ to give $(2 R, 3 R)-4 \mathrm{e}$ in yields of $72 \% .{ }^{1} \mathrm{H}$ NMR $\left(\mathrm{CDCl}_{3}\right) \delta 1.07$ (d, 3H, $\left.\mathrm{CH}_{3}\right), 2.40-2.47\left(\mathrm{~m}, 2 \mathrm{H}, \mathrm{CH}_{2}\right)$,

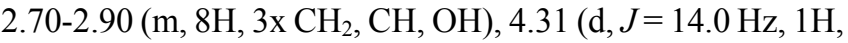
$\left.\mathrm{CH}_{2}\right), 4.50\left(\mathrm{~d}, J=14.0 \mathrm{~Hz}, 1 \mathrm{H}, \mathrm{CH}_{2}\right), 6.68-6.85(\mathrm{~m}, 4 \mathrm{H}), 7.22-$ $7.33(\mathrm{~m}, 2 \mathrm{H}), 8.10(\mathrm{~s}, 1 \mathrm{H}), 8.13(\mathrm{~s}, 1 \mathrm{H}), 10.2$ (s, 1H); FT-IR (KBr): 3211, 2766, 1752, 1602, 934; FAB-MS m/z 484.5 (Calcd. for $\mathrm{C}_{25} \mathrm{H}_{27} \mathrm{~F}_{3} \mathrm{~N}_{6} \mathrm{O}: 484.52$ ).

Compounds $\mathbf{4 a - d}, \mathbf{4 f - y}$ were prepared from their corresponding indole derivatives 3a-d, 3f-y according to the same protocol as described for compound $4 \mathbf{e}$.

Synthesis of $(2 R, 3 R)$-2-(2,4-difluorophenyl)-3-[4-(5,6-dichloro-1 H-indol-3-ylmethyl)-piperazin-1-yl]-1-(1H-1,2,4-triazol-1-yl)butan-2-ol (4t). yields : 66\%; ${ }^{1} \mathrm{H}$ NMR $\left(\mathrm{CDCl}_{3}\right) \delta 1.12$ (d, 3H, $\mathrm{CH}_{3}$ ), 2.21-2.67 (m, 9H, $\left.\mathrm{CH}_{2}, \mathrm{OH}\right), 3.31$ (s, 1H, CH), $3.32\left(\mathrm{~d}, 2 \mathrm{H}, \mathrm{CH}_{2}\right), 4.01\left(\mathrm{~d}, J=14.0 \mathrm{~Hz}, 1 \mathrm{H}, \mathrm{CH}_{2}\right), 4.34(\mathrm{~d}, J=$ $\left.14.0 \mathrm{~Hz}, 1 \mathrm{H}, \mathrm{CH}_{2}\right), 6.66-6.74(\mathrm{~m}, 3 \mathrm{H}), 7.07-7.11(\mathrm{~m}, 2 \mathrm{H}), 8.22$ (s, 1H), 8.24 (s, 1H), 10.1 (s, 1H); FT-IR (KBr): 3180, 2750, $1728,1626,894$; FAB-MS $m / z 534.1$ (Calcd. for $\mathrm{C}_{25} \mathrm{H}_{26} \mathrm{Cl}_{2} \mathrm{~F}_{2}$ $\mathrm{N}_{6} \mathrm{O}: 534.15$ ).

Evaluation of in vitro antifungal activity. Seven strains of Candida albican (ATCC64548, ATCC 26310, ATCC 90028, ATCC MYA-1003), Cryptococcus neoformans (ATCC 24065), Candida krusei (ATCC 6258), and Asregillus fumigatus (ATCC 16424) were used. These 7 strains have been generally used to evaluate anti-fungal activity. These strains were obtained from ATCC and subcultured in the laboratory and used for experiments. The prepared test article was serially diluted with RPMI 1640 medium to make final concentration range of $0.488-500$ $\mathrm{mg} / \mathrm{mL}$ in sterilized microtubes. Fungal strains used this study were inoculated on YM agar, Potato dextrose agar and Sabouraud's agars. The inoculated agar plates were incubated for enough days. The spore suspensions of Cryptococcus neoformans and Candida krusei strains were prepared in $0.85 \%$ saline 
(the other strains in saline with $0.2 \%$ tween 20 ), and were measured absorbance and transmittance at $530 \mathrm{~nm}$. The spore suspension of Fungal strains were adjusted to 0.108 of absorbance and was 1:50 diluted with RPMI 1640 medium. Then another 1:20 dilution was made to have $1 \times 10^{3}-5 \times 10^{3} \mathrm{CFU} / \mathrm{mL}$. The spore suspensions of the other strains were adjusted with sterile saline to $80-82 \%$ of transmittance and were 1:50 diluted with RPMI 1640 medium to make $0.4 \times 10^{4}-5 \times 10^{4} \mathrm{CFU} / \mathrm{mL}$. Autoclaved 96-well microplate was prepared in advance, and $0.1 \mathrm{~mL}$ of series of dilutions of the test article and $0.1 \mathrm{~mL}$ of spore suspensions were mixed in each well of the microplate to have concentration range of $0.244-250 \mathrm{mg} / \mathrm{mL}$. And then $25 \mu \mathrm{L}$ of alarmarblue (Biosource) was added into the well. Two wells were assigned for each concentration level to make duplicates. After 24 hour and 72 hour of incubation, the absorbance bands of the contents of the well were measured with Microplate reader (SOFTmax PRO, Molecular Devices) and observations with the naked eye were also referred. The results were presented as Minimum Inhibitory Concentration (MIC). The concentration of each test strains, at which the growth was inhibited by $80 \%$ compared to the negative control, was determined.

Acknowledgments. The author would like to thank Dr. Oak, Minho for his insightful discussion in preparation for this manuscript and for his invaluable assistance in processing the bioassays.

\section{References}

1. (a) Fridkin, S. K.; Jarvis, W. R. Clin. Microbiol. Rev. 1996, 9, 499. (b) Farowski, F.; Vehreschild, J. J.; Cornely, O. A. Future Microbiol. 2007, 2, 231.

2. Aoyama, Y.; Yoshida, Y.; Sato, R. J. Biol. Chem. 1984, 259, 1661.

3. (a) Sun, Q.; Xu, J.; Cao, Y.; Zhang, W.; Wu, Q.; Zhang, D.; Zhang, J.; Zhao, H.; Jiang, Y. Eur. J. Med. Chem. 2007, 42, 1226. (b) Uchida, T.; Kagoshima, Y.; Konosu, T. Bioorg. Med. Chem. Lett. 2009, 19, 2013.

4. (a) Singh, I. P.; Sidhu, I.; Palak, B. U.S. Patent 6,1333,485,2000. (b) Konosu, T.; Miyaoka, T.; Tajima, Y.; Oida, S. Chem. Pharm. Bull. 1991, 39, 2241. (c) Tasaka, A.; Tamura, N.; Matsushita, Y.; Kitazaki, T.; Hayashi, R.; Okonogi, K.; Itoh, K. Chem. Pharm. Bull. 1995, 43, 441. (d) Tasaka, A.; Tamura, N.; Matsushita, Y.; Teranishi, K.; Hayashi, R.; Okonogi, K.; Itoh, K. Chem. Pharm. Bull. 1993, 41, 1035.

5. (a) Ezquerra, J.; Pedregal, C.; Lamas, C.; Barluenga, J.; Pérez, M.; García-Martín, M. A.; González, J. M. J. Org. Chem. 1996, 61, 5804. (b) Tsuji, Y.; Kotachi, S.; Huh, K. T.; Watanabe, Y.J. Org. Chem. 1990, 55, 580. (c) Fujita, K.; Yamamoto, K.; Yamaguchi, R. Org. Lett. 2002, 4, 2691. (d) Carbonnelle, A.; Zamora, E. G.; Beugelmans, R.; Roussi, G. Tetrahedron Lett. 1998, 39, 4467.

6. (a) Galgiani, J.; Bartlett, M.; Ghannoum, M.; Espinel-Ingroff, A.; Lancaster, A.; Odds, F. NCCLS 1995, 15, 129. (b) Liao, R. S.; Robert, Rennie, P.; Talbot, J. A. Antimicrob. Agents Chemother. 2002, 46, 3236. (c) Davey, K. G.; Szekely, A.; Johnson, E. M.; Warnock, D. W. Antimicrob. Agents Chemother. 1998, 42, 439.

7. Mellado, E.; Garcia-Effron, G.; Alcázar-Fuoli, L.; Melchers, W. J. G.; Verweij, P. E.; Cuenca-Estrella, M.; Rodriguez-Tudela, J. L. Antimicrob. Agents Chemother. 2007, 51, 1897. 